\title{
The Temporal Dimension of Shopping Behavior
}

\author{
Jacob Hornik \\ The Coller School of Management, Tel Aviv University, Tel Aviv, Israel \\ Email: hornik@post.tau.ac.il
}

How to cite this paper: Hornik, J. (2021). The Temporal Dimension of Shopping Behavior. Journal of Service Science and Management, 14, 58-71.

https://doi.org/10.4236/jssm.2021.141005

Received: November 9, 2020

Accepted: February 16, 2021

Published: February 19, 2021

Copyright $\odot 2021$ by author(s) and Scientific Research Publishing Inc. This work is licensed under the Creative Commons Attribution International License (CC BY 4.0).

http://creativecommons.org/licenses/by/4.0/

\begin{abstract}
Shopping is a major household activity that consumes time and other resources. This paper represents an attempt to construct a unified model of shopping activity by drawing on the households' production approach. A formal treatment is presented that takes into account the explicit relationships between households' temporal and monetary resources, stage of family life cycle, their subjective shopping preferences, and shopping behavior. Emerged propositions make the study of time use for shopping increasingly amenable.
\end{abstract}

\section{Keywords}

Shopping Time, Household Production, Family Life-Cycle

\section{Introduction}

Some of the fundamental dimensions of household shopping behavior may be summarized by the factor time. Shopping is a major household activity that consumes time and other resources. Time is rapidly assuming a central place in households analysis (e.g., Feldman \& Hornik, 1981; Papastefanou \& Zajchowski, 2016). This development reflects, among other things, the increasing awareness that many consumption activities require the use of scarce resources, such as energy, information, money, space, and time (Cohen et al., 2020). Shopping is one households' activity which requires expenditures of most of these scarce resources. Of the various resources involved in shopping, time has been researched the least, although in most writings one would find the arguments that a shopping activity is an important and time-consuming activity (Berry, 1979; Granbois, 1977; Papastefanou \& Zajchowski, 2016; Atalay et al., 2017). However, shoppers' time expenditure has been recognized as an important and underutilized measure of shopper behavior and for stores strategies (Chetioui et al., 2020; Sohn \& Lee, 2017). 
Shopping, traditionally the domain of women, is being assumed to a varying degree by males in a growing number of households. American households spent, on the average, about seven hours a week for shopping in about three shopping trips. Sixty-three point four percent of this shopping time is spent by the wife alone, $27 \%$ by the husband and wife, and $9.5 \%$ by the husband alone (U.S. Bureau of Labor Statistics, 2016). In addition to the gender differences, research has also documented that households life cycle explains variations in the time spent on shopping activities (Kaplan \& Menzio, 2016; Papastefanou \& Zajchowski, 2016; Rich \& Jain, 1968). Also, those consumers are likely to spend more time for shopping activities if they place a high value on the benefits to be gained from such an activity relative to the benefits expected for other (nonshopping) activities (McDonald, 1994; Petrosky-Nadeau et al., 2016). The intent of this paper is to outline a theoretical scheme and formalize the theoretical structure in which decisions to allocate time for shopping activities can be understood. Therefore, the paper proceeds with an outline of the theoretical framework, followed by model specification, results and discussions. The paper ends with specific practical implications, as well as, pointing to some limitations, and future research.

\section{Theoretical Framework}

The theoretical base of this paper draws on a modified economic production function model (Gronau, 1977); on the life cycle concept in household time behavior (e.g., Chapela, 2013; Landon \& Locander, 1978); and the subjective preference propositions in time use studies (e.g., Festjens \& Janiszewski, 2015; Gonzalez-Chapela, 2006; Hornik, 1982). To this end, a formal treatment of dynamic shopping model will be advanced that takes into account the explicit relationships between households' resources and their subjective preferences. This approach provides an opportunity for measuring time preferences by situational conditions to predict shopping behavior. Such a theoretical structure would seem to bring time use squarely into the spotlight as a determinant of shopping behavior.

\subsection{The Household Production Function}

The household production approach in economic theory emphasizes the fact that market goods and services are not themselves carrying utility but are rather inputs in a process that generates commodities (or characteristics) which, in turn, yield utility (Etgar, 1978). A second feature is that market goods and services are not the only inputs in this process, the other input being the household's time. According to this approach (Becker, 1965) the household maximizes utility subject to the time and budget constraints where utility is a function of commodities, which are produced using market goods and time. This approach was extended to explain household behavior in diverse situations such as church attendance (Azzi \& Ehrenberg, 1975), demand for health (Grossman, 1972), 
education (Michael, 1973), transportation (Gronau, 1970), and even shopping for clothing (Mihip et al., 2018). The topic received further attention by several research streams concerning the effects of time pressure on consumer decision making (e.g. Berry, 1979), consumers' allocation of time to daily activities (e.g., Feldman \& Hornik, 1981), consumers' perception of time (e.g., Hornik, 1984) and attitudes towards queues, like multi line versus snake lines (e.g. Gronau, 1970). Furthermore, time has been shown to have cause-and-effect properties, as it can be an antecedent and a consequence of purchase behavior (McDonald, 1994). Many factors contribute to the length of a shopping trip. Such a framework can be also used for considering how households may determine their shopping activities. For example, Forsythe and Bailey (1996) purposed an enjoyment-based motivational framework for shopping behavior. Their findings show that shopping enjoyment is a viable motivational construct influencing time allocation to shopping and provided support for extending traditional utility maximization models to include in shopping behavior.

According to the economic approach households will assign values both to the benefits of shopping and the cost of time, effort, and money involved. The extent of the shopping activity (frequency and duration) is thus determined by the marginal rate; shopping continues until the value of an additional unit of shopping is equaled by its cost. Family differences occur because households differ in their value of time, which is thought to be subjectively valued according to the opportunity cost rule-the greater the number of activities competing for a unit of time, the greater its value (Anily et al., 1999; Festjens \& Janiszewski, 2015; Hamrick \& Hopkins, 2012). Time is further valued by its relationship with income, to the extent that time and money can be thought of as, at least partly, substitutable resources. For this reason the value of time becomes greater as one's income increases and the value of the next (marginal) dollar decreases.

Models of household production also recognize that the value of the changes for a households at various stages of its life cycle, and these changes include substitution toward relatively cheaper input factors of production (Chapela, 2013; Fernández-Villaverde \& Krueger, 2007). When income and consequently the value of time, is relatively high, the members works more, have less free time for shopping, and generally behave in ways which conserve time and use money relatively intensively.

\subsection{The Household Life Cycle}

In their study of time as a measure of household productivity, Walker \& Woods (1976) noted that household production changes over time within a given household. "The family is not a static entity but goes through life cycle stages of growth and contraction, with each stage requiring a different 'mix', quantitatively and qualitatively, of goods and services to meet the needs of family members" (p. 8). Therefore, by knowing the life cycle stage of the household, it would be possible to predict how much time would have to be spent to produce the 
goods and services a household needs to function as a unit (Ferber \& Biranbaum, 1977).

Family life cycle (FLC) appears to have much potential for explaining time behavior because it is both multidimensional and dynamic (Landon \& Locander, 1978; Zuzanek \& Smale, 2002). Its multidimensional nature is attributed to the fact that FLC is a composite of several important demographic variables. FLC is dynamic because it accounts for the changing family needs and structure over time. Arndt \& Gronmo (1977) in their treatment of time in shopping behavior explicitly recognize the importance of FLC as a determinant of time devoted to shopping activities. In addition, they speculate that shopping may satisfy various subjective needs such as diversion, self-gratification, and social interaction (Wiese, 2016).

The early literature considered the market for goods and services as the prototypical setting in which buyers and sellers are engaged in a costly and time consuming process to find and establish trading relationships (Granbois, 1977). Companies exert effort and consume resources in order to promote their products and maintain their customer relationships. Consumers spend time searching, selecting and purchasing to obtain goods and services, adding and removing items from their consumption basket. Departures from market clearing assumptions introduce a range of possible price determination mechanisms that have important implications for equilibrium allocations in the long run and over the family life-cycle.

\subsection{Subjective Preference}

Time in the household production function literature is only important as a scarce resource which must be allocated among alternative activities. The tangible outputs of these activities comprise the arguments of the household utility function. A measure of concentration of the use of time, with an application to the pattern of daily leisure activities (Chapela, 2013; Gronau, 1977). Therefore, the pattern of time allocation for households' influences shopping activities only through the production and consumption of commodities, not through derived gratifications from shopping activities themselves (Petrosky-Nadeau et al., 2016). Therefore, the concept of shopping time should consider that consumers spend time and money to acquire products and services, but they also use time as a substitute for money and will continue to search until the expected shopping savings are less than the costs of time.

Shopping trips may involve gratifications that are beyond the primary functions of search and exchange. Some motives for shopping include diversion and recreation, self-gratification and reward, learning about new trends, physical activity or exercise, and sensory stimulation, as well as the satisfaction of performing an activity seen as an integral part of one's role (Granbois, 1977; Hornik, 1982; Papastefanou \& Zajchowski, 2016). Social motives involve social experience such as, encounters with friends and watching other people, communica- 
tion with others having a similar interest, peer-group attraction (such as teenagers find in record stores), the opportunity to command attention and respect by being "waited on", and the pleasure derived from bargaining (Hornik \& Zakay, 1996). An implied proposition here is that shopping activities may well be perceived and valued differently by different households depending on their subjective preferences and whether the activity is felt to be one of only immediate gratifications, or rather one of "investment" in some long-term socio-psychological fulfillments. Moreover, different shopping activities have different functions and characteristics and therefore, might correspond to different temporal behavior. Also, given that shopping entails expenditure of money and time, unlike money, time is not expandable and its value differs among individuals. Consumers who are prone to view time as a scarce resource are more sensitive to the time costs of activities, as differences in time orientation shapes perceptions of convenience (Park et al., 1989). According to Berry (1979), the greater the time costs associated with a service, the lower the consumers' perception of service convenience. Prior research affirms a positive link between service convenience and customer satisfaction, however, scholars have urged for the inclusion of shopping value and other retail outcomes to better comprehend the process (Vasic et al., 2019; Wiese, 2016).

\section{The Basic Model}

The proposed model rests on the theory of choice under uncertainty. Following our conceptual background, a central proposition in the theory is that if, in a given period, two activities are mutually exclusive, one will choose between them by comparing their expected utilities. This proposition suggests that households spend shopping time as if they were to maximize their expected utilities subject to environmental constraints and limited resources. It is further assumed that households confronted with choice situations behave as if they sort out and arrange their preferences, which, in turn, direct their choices. Thus, this assumes a quasi-concave utility function:

$$
U_{1}=U\left(Z_{1}, Z_{2}, \cdots, Z_{t}, \cdots, Z_{n}, e\right)
$$

where $Z$ represents households' consumption in period $t$, and $e$ the expected value of a shopping activity. It is assumed that the household knows his current and future market wages, which are taken as predetermined in the model. Consumption in period $t$ is expressed by the production function which transforms the households' purchases of a composite market good $x$ and the time allocation $h$ to consumption into units of the final consumption commodity $(Z)$. The function is assumed to be the same in each period and to be continuously differentiable and concave:

$$
Z_{t}=Z\left(x_{t}, h_{t}\right) \text { for all } t
$$

Expected benefit of shopping activities is assumed to be continuous differentiable, concave function of the time spent in shopping $(h)$ : 


$$
e=e\left(h_{1}, h_{2}, \cdots, h_{n}\right)
$$

Let $p$ stand for the price of the market good in any period of time, $w$ for the wage rate in period $t, i$ for a constant market rate of interest, $v$ for other (non labor) sources of income in each period, and 1 for hours of work in $t$. Assuming that the household intends to leave no estate, his lifetime discounted income constraint is given by:

$$
\sum_{t=1}^{n}\left[p x_{t} /(1+i)^{t-1}\right]=\sum_{t=1}^{n}\left[\left(v+w_{t} 1_{t}\right) /(1+i)^{t-1}\right]
$$

If $T$ is the stock of time available per period, the household's time constraint is given by:

$$
T=h_{t}+h_{t}+1_{t}
$$

where $h_{t}, h_{t} 1_{t}>0$ for all $t$.

The preceding comprises a well-defined maximization problem. The production function can now be substituted into the utility function (1) to yield a composite function, and the time constraint can be solved for 1 and substituted into (4) to yield a "full-wealth" constraint. Taken together the functions allow the use of the Lanrangian function for the problem:

$$
\begin{aligned}
L_{1}= & U\left[Z\left(x_{1}, h_{1}\right), Z\left(x_{2}, h_{2}\right), \cdots, Z\left(x_{n}, h_{n}\right), e\left(h_{1}^{\prime}, \cdots, h_{n}^{\prime}\right)\right] \\
& +\lambda\left\{\sum_{t=1}^{n}\left[p x_{t} /(1+i)^{t-1}\right]-\sum_{t=1}^{n}\left[\left(v+w_{t} 1_{t}\right) /(1+i)^{t-1}\right]\right\}
\end{aligned}
$$

substituting the time constraints results in

$$
\begin{aligned}
L_{1}= & U\left[Z\left(x_{1}, h_{1}\right), \cdots, Z\left(x_{n}, h_{n}\right), e\left(h_{1}^{\prime}, \cdots, h_{n}^{\prime}\right)\right] \\
& +\lambda\left\{\sum_{t=1}^{n}\left[p x_{t} /(1+i)^{t-1}\right]-\sum_{t=1}^{n}\left[\left(v+w_{t}\left(T-h_{t}-h_{t}^{\prime}\right)\right) /(1+i)^{t-1}\right]\right\}
\end{aligned}
$$

The first order condition requires that at the optimum

$$
\frac{\partial e}{\partial h_{t}^{\prime}}=w_{t} \text { for all } t
$$

If it is assumed that the household faces constant wage rates over lifetime, the first-order conditions require that at the optimum.

$$
\frac{\partial e / \partial h_{t}^{\prime}}{\partial e / \partial h_{t-1}^{\prime}}=(1+i)^{-1} \text { for all } t
$$

\subsection{Family Life Cycle}

The condition above requires that households reallocate their time toward shopping activities with advancing age. If, for a household, the marginal product or an additional unit of time for shopping is the same in period $t-1$ and $t$, when they devote the same amount of time to shopping activities during the two period, then Equation (9) implies that the number of time units per period allocated to shopping increases with age.

Empirical studies report a distinctive curve of shopping associated with FLC (Rich \& Jain, 1968; Petrosky-Nadeau, 2016). In the early family years (newly 
married), shopping time is generally low, rising during middle years (full nest), and declining later FLC (empty nest). The explanation has been that in early FLC families are unsettled, mobile, no children, etc. Advanced age, on the other hand, brings fatigue and social withdrawal that lower the rate of shopping activities. More shopping time comes with extended residence, home ownership, children in school, etc. (Chetioui et al., 2020; Granbois, 1977). Similarly, when working time can be chosen freely, shopping effort and working time covary negatively. Hence, a rise in the hourly wage raises hours if the substitution effect dominates the income effect (Cohen at al., 2020). This leads to less shopping time.

The discussion so far is based on the assumption that one's wage rates are constant over lifetime. However, if for two adjacent time periods a household's wage rate varies Equation (9) becomes:

$$
\frac{\partial e / \partial h_{t}^{\prime}}{\partial e / \partial h_{t-1}^{\prime}}=\left(w_{t} / w_{t-1}\right)(1+i)^{-1}
$$

Thus, all other things equal, the more rapid the rate of wage increase, the slower the rate at which units of time allocated to shopping activities will increase with age. In other words, when households' marginal costs of investing in shopping activities rise less rapidly with age, they will allocate more time to shopping.

The effect of a change in non-labor income on shopping can also be calculated under the conditions of optimality; an increase in non-labor income leads to an increase in the time allocated to shopping that is, $a h / a v>0$.

\subsection{The Gratification Effect}

Although consumers tend to optimize their time given the opportunity cost of time and shoppers' time-sensitivity, there is enough evidence to believe that time spent on shopping is an important determinant of purchasing gratifications. Several studies have found a direct and significant relationship between the time a customer remains in a store and gratifications (e.g. Wiese, 2016). Accordingly, research has found that the longer the shopper stays in the store, the more she or he is exposed to in-store stimuli and therefore the higher the purchasing outcomes (Park et al., 1989). While the preceding analysis has been simplified by ignoring subjective preferences among shopping activities and gratification derived from such action, the following utility function takes these into consideration expressed by:

$$
U_{2}=U_{2}\left(Z_{1}, s_{1}, \cdots, Z_{n}, s_{n}, e\right)
$$

where $s$ is the subjective consumption value of shopping activities in period $t$. The function is assumed to be continuous concave, and to represent the households' time allocation to shopping during the period:

$$
s_{t}=s_{t}\left(h_{1}^{\prime}, h_{2}^{\prime} h_{n}^{\prime}\right) \text { for all } t \text {. }
$$

By way of substitution we obtain: 


$$
\begin{aligned}
L_{1}= & U_{2}\left[Z\left(x_{1}, h_{1}^{\prime}\right), s_{1}\left(h_{1}^{\prime}, \cdots, h_{n}^{\prime}\right), \cdots, Z\left(x_{n}, h_{n}^{\prime}\right), s_{n}\left(h_{1}^{\prime}, \cdots, h_{n}^{\prime}\right)\right] \\
& +\lambda\left\{\sum_{t=1}^{n}\left[p x_{t} /(1+i)^{t-1}\right]-\sum_{t=1}^{n}\left[\left(v+w_{t}\left(T-1_{t}-h_{t}^{\prime}\right)\right) /(1+i)^{t-1}\right]\right\}
\end{aligned}
$$

Clearly, the previous implications concerning the impact of wage rate and nonlabor income on shipping time remains unchanged. However, the implication of equation [10] with respect to intertemporal allocation of time to shopping is given by:

$$
\frac{\left[\left(\partial U / \partial s_{t}\right)\left(\partial s_{t} / \partial h_{t}^{\prime}\right)+(\partial U / \partial e)\left(\partial e / \partial h_{t}^{\prime}\right)\right]}{\left[\left(\partial U / \partial s_{t-1}\right)\left(\partial s_{t-1} / \partial h_{t-1}^{\prime}\right)+(\partial U / \partial e)\left(\partial e / \partial h_{t}^{\prime}\right)\right]}=\left[\left(w_{t} / w_{t-1}\right)(1+i)^{-1}\right] \text { for all } t
$$

That is, even if a household faces a constant wage rate during the two periods, there may no longer be any reason for proposing that shopping time should increase with FLC because of the subjective elements in the activities. However, if the expected value of the activity is significantly more important than immediate satisfaction, the previous implications would hold. Formally this requires aUlbe to be substantially larger than au/ $U s$ for all $t$. Thus, factors which increase the current gratifications that households derive from a shopping activity would lead to an increase in the time allocated to shopping.

\section{Results}

One of the model's important implications is that, all other things equal, the more rapid the rate of wage increase, the slower the rate to which time allocated to shopping activities will increase with age. The stresses and demands of modern day life mean that consumers are increasingly feeling a sense of time scarcity. Time paucity leads consumers to place a premium on shopping options that are quick and easy (Chapela, 2013). Consequently, along with the combined forces of other economic and sociocultural factors, a steady rise in consumer demand for convenience from prepurchase to postpurchase is an ever-present trend in the marketplace (Gronau, 1977). Even if the household faces a constant wage rate during two or more periods of time there is no compelling reason to suggest that shopping time should increase with FLC because of possible variations in immediate gratifications derive from the activity. This suggests that wage-earning profiles rather than cross-sectional comparisons of income might be better predictors of the amount of shopping time. In fact, the model predicts that households facing an upward-slopping age-earning profile will decrease the time intensity of their shopping activities over the course of their life cycle. This could be achieved, partly, by reallocating their time toward less time-intensive forms of shopping. In other words, households may substitute more time intensive shopping activities for less time intensive ones. They may, overtime, adopt a whole new set of shopping behavior as shopping technology enables them to derive the same basic set of shopping benefits with less time and more money. For example, to switch to online shopping (Mpinganjira, 2015) to replace conventional food stores with in-home shopping (Van Droogenbroeck \& Hove, 2020), use 
convenience store (e.g., 7-eleven), patronize less crowed stores (Forsythe \& Bailey, 1996), switch to-catalog and/or mail order shopping, or even use personal "errand" services ranging from shopping for parties to picking up households' dry cleaning. Also, the model suggests that shoppers who place high economic value on time, the effects of service convenience are greater on hedonic value. Conversely, those who place low economic value on time, effects of service convenience are greater on utilitarian value.

\section{Discussion}

This paper presented a formal model of households' use of time for shopping. Drawing primarily on the production function approach, the paper treats the cost of time as the costs of market goods in a model of choice. By viewing time as a resource, an intertemporal utility maximization model was developed which includes propositions concerning the optimal allocation of time and the shape of shopping activities throughout the FLC. Whereas some of the model's implications are congruent with the more recent empirical evidence (e.g., U.S. Bureau of Labor Statistics, 2016; Atalay et al., 2017), others call for a more critical examination of short-term changes in time spent for shopping. Overall, the results support studies by Arndt \& Gronmo (1997) and Hornik (1982), on a role for situational variables in predicting shopping time; the work by Petrosky-Nadeau et al. (2016) on individual time preferences; and the study by Chapela (2013), showing relationships between time budgets, leisure time activities. The model results collaborate with the social approach to shopping. For many households, the problem is not to save time, but how to spend time, and to maintain desirable identification with their society (Arndt \& Gronmo, 1997). It may be a result of the modern society that retailers have to take on the distribution tasks which otherwise should have been performed by individuals, friends, family members or other social organizations. However, as long as the modern online and traditional offline stores continue to be involved with such important time value functions, this temporal function should not be ignored by managers or by researchers.

\subsection{Practical Implications}

This approach suggests that consumers' store knowledge and the time available for shopping may affect many types of in-store shopping decisions. All the model factors might also have an effect on levels of unplanned buying, brand switching due to difficulty in locating preferred brands/products, and the level of purchase volume deliberation. Several managerial implications might be derived from this approach. As our findings indicate, store managers should continue to create an environment that encourages patrons to stay longer and thus to make more purchases. Time that shoppers spend in stores should become an explicit element in store management. Variations in patterns of time expenditures may be used to define market segments. For example, FLC, knowing that older and 
retired people and social family shoppers spend longer times shopping, retailers could set up play areas for the children of the women or men shoppers and provide extra services for the retirees. Store layout, merchandising, staffing and in-store promotions should encourage consumers to stay inside a store as long as possible, which will result in higher spending per customer. Orientation aids in high traffic areas or consumer choice points can help shoppers find their way by improving the accessibility of information (Titus \& Everett, 1995). Embracing newer forms of technology include mobile phone applications that are designed to provide time-poor shoppers with interactive maps of the store or mall. Also, introduce applications that can also guide a visitor to a mall, locate a vacant parking space quickly, and lot the vehicle's position on a plan of the mall. Shoppers are guided to their store sections, and alerted of special offers inside the store or mall. An example of one such application is Fastmall, which is designed to make the shopping experience simpler and conserve time. This type of application is also likely to fare well with younger shoppers who are comfortable with using technology.

In addition, there is a difference between online shoppers and offline shoppers. Saving time is one of the most influential factors in online shopping. Time is the main resource that consumers spend when they purchase online or in traditional stores (Bucklin, 1966). This is because online shoppers are concerned with time saving and choice, while offline consumers are anxious about security, privacy, and delivery on time (Gonzalez-Chapela, 2006). The advantage of online commerce is related to purchase simplicity and the reduction of time spent on shopping (Granbois, 1977). One of the most significant problems people generally deal with concerns the perceived time pressures. According to Hornik \& Zakay (1996), time pressures present the degree one realizes there is no time left in relation to daily obligations and chores. Since online commerce can be completed anywhere and anytime, this greatly simplifies the buying process by purchasing online, consumers avoid travel and parking time, and in store queuing.

\subsection{Limitations and Future Research}

Although this study is based on a comprehensive conceptualization, there are some limitations. Like most business research, the approach used in this paper was a macro perspective. More precise information about consumer shopping time and gratification should be obtained from microeconomic data such as consumer surveys.

Although our conceptualization suggest that time is positively related to purchasing outcomes in most retail environments, the task may not be so straightforward for grocery retailers. Grocery shopping constitutes a routine type of consumer behavior and shoppers tend to optimize their time and money expenditures (Kongarchapatara \& Shannon, 2016). Since some consumers are more time sensitive than others and are able to shop quickly in a grocery envi- 
ronment in which they are familiar, they are able to purchase large quantities of foods in a relatively short time, with the result that their shopping yields much higher purchases per minute or hour than other consumers. Examination of time use has been only considered in our model from the factor of economic value of time. Although this factor has commonly emerged as one that explains the greatest variance across an array of studies, it is likely that other factors not considered in this paper such as temporal orientation could play a role in perceptions of the shopping experience. Future investigations can employ more dimensions of time use to garner a better grasp of how attitudes towards time pervade use of time in shopping.

Another limitation of our approach is the need to identify and compare the pre and post purchasing time (Arndt \& Gronmo, 1997). Thus, a good framework for thinking about shopping time is to disentangle this time between pre-purchase efforts, (which may in practice occur while purchasing other goods), and post-purchasing time which transforms time into actual purchasing. Employing broader scale of before and after shopping activity would provide greater insight into the effects of each of the suggested dimensions on the shopping experience. For instance, high economic time value shoppers have a tendency to carefully plan their time in advance, hence the effects of decision or access convenience, which occurs prior to reaching the shopping destination, would be stronger.

Additional insights are necessary in order to determine the generalizability of the model to different shopping situations such as online shopping (e.g. Chetioui et al., 2020; Li et al., 2020; Mpinganjira, 2015; Vasic et al. 2019). As noted earlier, some shopping activities provide basically immediate benefits in the form of search and exchange. Others contain more enduring socio psychological gratifications. For example, shopping for soft goods such as clothing and yard products seem to be relatively more involved and provide some of the mentioned socio-psychological elements (Mihip et al., 2018). On the other hand, food shopping offers less psychological gratifications but a means of acquiring needed economic resources and therefore requires more frequent but shorter shopping trips (Kongarchapatara \& Shannon, 2016). Also, to gain insight into the "window shopping" phenomenon where time spent, at least partially, is to search for market information (Petrosky-Nadeau et al., 2016). More ambitious endeavors, such as the estimation of the household production function and the value of different shopping activities might be advanced. Despite some limitations, the results of this model offer useful insights into time-consumer behavior relationships with some valuable managerial implications and direction for further research. Given the right data, it is hoped that this model will facilitate their realization.

\section{Conflicts of Interest}

The author declares no conflicts of interest regarding the publication of this paper. 


\section{References}

Anily, S., Hornik, J., \& Israeli, M. (1999). Inferring the Distribution of Households' Duration of Residence from Data on Current Residence Time. Journal of Business \& Economic Statistics, 17, 373-381. https://doi.org/10.1080/07350015.1999.10524826

Arndt, J., \& Gronmo, S. (1997). The Time Dimension of Shopping Behavior: Some Empirical Findings. In W. D. Perreault Jr. (Ed.), Advances in Consumer Research (Vol. 4, pp. 230-235). Ann Arbor, MI: Association for Consumer.

Atalay, A. S., Bodur, H. O., \& Bressoud, E. (2017). When and How Multitasking Impacts Consumer Shopping Decisions. Journal of Retailing, 93, 187-200. https://doi.org/10.1016/j.jretai.2016.09.001

Azzi, C., \& Ehrenberg, R. (1975). Household Allocation of Time and Church Attendance. Journal of Political Economy, 83, 27-56. https://doi.org/10.1086/260305

Becker, G. (1965). A Theory of the Allocation of Time. The Economic Journal, 75, 493-517. https://doi.org/10.2307/2228949

Berry, L. L. (1979). The Time-Buying Consumer. Journal of Retailing, 55, 58-68.

Bucklin, L. P. (1966). Testing Propensities to Shop. Journal of Marketing, 30, 22-27. https://doi.org/10.1177/002224296603000106

Chapela, J. G. (2013). A Measure of Concentration of the Use of Time, with an Application to the Pattern of Daily Leisure Activities. Electronic International Journal of Time Use Research, 10, 9-37. https://doi.org/10.13085/eIJTUR.10.1.9-37

Chetioui, Y., Lebdaoui, H., \& Chetioui, H. (2020). Factors Influencing Consumer Attitudes toward Online Shopping: the Mediating Effect of Trust. EuroMed Journal of Business. https://doi.org/10.1108/EMJB-05-2020-0046

Cohen, J., Ericson, K. M., Laibson, D., \& White, J. M. (2020). Measuring Time Preferences. Journal of Economic Literature, 58, 299-347. https://doi.org/10.1257/jel.20191074

Etgar, M. (1978). The Household as a Production Unit. Research in Marketing, 1, 79-98.

Feldman, L. P., \& Hornik, J. (1981). The Use of Time: An Integrated Conceptual Model. Journal of Consumer Research, 7, 407-419. https://doi.org/10.1086/208831

Fernández-Villaverde, J., \& Krueger, D. (2007). Consumption over the Life Cycle: Facts from Consumer Expenditure Survey Data. The Review of Economics and Statistics, 89, 552-565.

Festjens, A., \& Janiszewski, C. (2015). The Value of Time. Journal of Consumer Research, 42, 178-195.

Ferber, M. A., \& Birnbaum, B. G. (1977). The New Home Economics: Retrospects and Prospects. Journal of Consumer Research, 4, 19-28. https://doi.org/10.1086/208675

Forsythe, S. M., \& Bailey A. W. (1996). Shopping Enjoyment, Perceived Time Poverty, and Time Spent Shopping. Clothing and Textiles Research Journal, 14, 185-191. https://doi.org/10.1177/0887302X9601400303

Gonzalez-Chapela, J. (2006). On Measuring Heterogeneity in the Use of Time. Electronic International Journal of Time Use Research, 3, 110-111. https://doi.org/10.13085/eIJTUR.3.1.110-119

Granbois, D. H. (1977). Shopping Behavior and Preferences. In R. Ferber (Ed.), Selected Aspects of Consumer Behavior (pp. 59-98). Washington DC: National Science Foundation.

Gronau, R. (1970). The Value of Time in Passenger Transportation. Occas. Paper No. 101, New York: National Bureau of Economic Research. 
Gronau, R. (1977). Leisure, Home Production, and Work-The Theory of Allocation of Time Revisited. Journal of Political Economy, 85, 1099-1123. https://doi.org/10.1086/260629

Grossman, M. (1972). On the Concept of Health, Capital and the Demand for Health. Journal of Political Economy, 80, 293-235. https://doi.org/10.1086/259880

Hamrick, K. S., \& Hopkins, D. (2012). The Time Cost of Access to Food-Distance to the Grocery Store as Measured in Minutes. International Journal of Time Use Research, 9, 28-58.

Hornik, J. (1982). Situational Effects of the Consumption of Time. Journal of Marketing, 46, 44-55. https://doi.org/10.2307/1251361

Hornik, J. (1984). Subjective vs. Objective Time Measures: A Note on the Perception of Time in Consumer Behavior. Journal of Consumer Research, 11, 615-618. https://doi.org/10.1086/208998

Hornik, J., \& Zakay, D. (1996). Psychological Time: The Case of Time and Consumer Behaviour. Time \& Society, 5, 385-397. https://doi.org/10.1177/0961463X96005003007

Kaplan, G., \& Menzio, G. (2016). Shopping Externalities and Self-Fulfilling Unemployment Fluctuations. Journal of Political Economy, 124, 771-825. https://doi.org/10.1086/685909

Kongarchapatara, B., \& Shannon, R. (2016). The Effect of Time Stress on Store Loyalty: A Case of Food and Grocery Shopping in Thailand. Australasian Marketing Journal, 24, 267-274. https://doi.org/10.1016/j.ausmj.2016.10.002

Landon, L. E., \& Locander, W. B. (1978). Family Life Cycle and Leisure Behavior Research. In W. L. Wilkie (Ed.), Advances in Consumer Research (Vol. 6, pp. 133-138). Ann Arbor, MI: Association for Consumer Research.

Li, X., Zhao, X. D., \& Pu, W. (2020). Measuring Ease of Use of Mobile Applications in e-Commerce Retailing from the Perspective of Consumer Online Shopping Behaviour Patterns. Journal of Retailing and Consumer Services, 55, 102-121. https://doi.org/10.1016/j.jretconser.2020.102093

McDonald, W. J. (1994). Time Use in Shopping: The Role of Personal Characteristics. Journal of Retailing, 70, 345-365. https://doi.org/10.1016/0022-4359(94)90004-3

Michael, R. T. (1973). Education in Non-Market Production. Journal of Political Economy, 81, 306-327. https://doi.org/10.1086/260029

Mihip, M., Ivan-Damir, A., \& Milakovip, I. K. (2018) Time Spent Shopping and Consumer Clothing Purchasing Behaviour. Ekonomski pregled, 69, 89-105. https://doi.org/10.32910/ep.69.2.1

Mpinganjira, M. (2015). Using Online Service-Scape to Appeal to Customers: A Focus on Hedonic Shoppers. The Retail and Marketing Review, 11, 61-75.

Papastefanou, G., \& Zajchowski, D. (2016). Time for Shopping-social Change of Time Use for Shopping Activities 1990-2012. Electronic International Journal of Time Use Research, 13, 109-113. https://doi.org/10.13085/eIJTUR.13.1.109-131

Park, C. W., Iyer, E. S., \& Smith, D. C. (1989). The Effects of Situational Factors on In-Store Grocery Shopping Behavior: The Role of Store Environment and Time Available for Shopping. Journal of Consumer Research, 15, 422-433. https://doi.org/10.1086/209182

Petrosky-Nadeau, N., Wasmer, E., \& Zeng, S. (2016). Shopping Time. Economics Letters, 143, 52-60. https://doi.org/10.1016/j.econlet.2016.02.003

Rich, S. U., \& Jain, S. C. (1968). Social Class and Life Cycle as Predictors of Shopping Behavior. Journal of Marketing Research, 5, 41-49. 
https://doi.org/10.1177/002224376800500105

Sohn, H. K., \& Lee, T. G. (2017). Tourists' Impulse Buying Behavior at Duty-Free Shops: The Moderating Effects of Time Pressure and Shopping Involvement. Journal of Travel \& Tourism Marketing, 34, 341-356. https://doi.org/10.1080/10548408.2016.1170650

Titus, P. A., \& Everett, P. B. (1995). The Consumer Retail Search Process: A Conceptual Model and Research Agenda. Journal of the Academy of Marketing Science, 23, 106-119.

U.S. Bureau of Labor Statistics (2016). The American Time Use Survey (ATUS).

Van Droogenbroeck, E., \& Hove, L. V. (2020). Intra-Household Task Allocation in Online Grocery Shopping: Together Alone. Journal of Retailing and Consumer Services, 56, Article ID: 102153. https://doi.org/10.1016/j.jretconser.2020.102153

Vasic, N., Kilibarda, M., \& Kaurin, T. (2019). The Influence of Online Shopping Determinants on Customer Satisfaction in the Serbian Market. Journal of Theoretical and Applied Electronic Commerce Research, 14, 2-18. https://doi.org/10.4067/S0718-18762019000200107

Walker, K., \& Woods, M. (1976). Time Use: A Measure of Household Production of Family Goods and Services. Washington DC: American Home Economic Association.

Wiese, M. (2016). Ensuring Satisfied, Committed Shoppers-Store Variety or Entertainment? The Retail and Marketing Review, 12, 54-69.

Zuzanek, J., \& Smale, B. J. (2002). Life-Cycle and Across-the-Week Allocation of Time to Daily Activities. In Time Use Research in the Social Sciences (pp. 127-153). Boston, MA: Springer. 